\title{
Apical inflow is associated with increased energy loss during left ventricular diastole in patients with a repaired atrioventricular septal defect: a 4D flow MRI study
}

\author{
Mohammed SM EIBaz ${ }^{1 *}$, Arno Roest ${ }^{2}$, Emmeline Calkoen ${ }^{2}$, Patrick J de Koning ${ }^{1}$, Boudewijn PF Lelieveldt ${ }^{1,3}$, \\ Rob J van der Geest ${ }^{1}$, Jos J Westenberg ${ }^{1}$
}

From 19th Annual SCMR Scientific Sessions

Los Angeles, CA, USA. 27-30 January 2016

\section{Background}

Patients after atrioventricular septal defect (AVSD) repair have aberrant atrioventricular valve morphology resulting in a disorganized left ventricular (LV) inflow [1] with an increased amount of inflow reaching the apical level of the LV and retaining there during the subsequent systole [1]. This may elevate energy loss in LV flow due to friction. We aimed to evaluate the association between the percentages (retained) apical inflow with viscous energy loss during diastole in AVSD-repaired patients compared to healthy controls using 4D flow MRI.

\section{Methods}

21 AVSD-repaired patients (age: $33 \pm 9$ years) and 16 healthy controls (age: $35 \pm 11$ years, $\mathrm{p}=0.52$ ) underwent free-breathing whole-heart 4D flow MRI at 3T(VENC $=150 \mathrm{~cm} / \mathrm{s}$ in all directions, spatial resolution $2.3 \times 2.3 \times$ $3.0-4.2 \mathrm{~mm}^{3}, 30$ retrospectively reconstructed phases over a cardiac cycle). The workflow in [1] was used to compute, relative to total inflow, percentages of apical inflow (AI\%: inflow that reaches apical level during diastole), and retained apical inflow (RAI\%: part of apical inflow that is not ejected during subsequent systole). The LV was segmented and the total non-turbulent viscous energy loss was computed over diastole (EL_diastole in Joule (J)) using the Navier-Stokes energy equations [2]. The 95\%CI (confidence interval) for AI\% and RAI\% was computed from healthy controls. Patients were then classified as: below or

${ }^{1}$ Division of Image Processing, Radiology, Leiden University Medical Center (LUMC), Leiden, Netherlands

Full list of author information is available at the end of the article above upper limit of $95 \% \mathrm{CI}$ of $\mathrm{AI} \%$, and below or above upperlimit of $95 \% \mathrm{CI}$ of RAI\%. Parameters were compared using Student's t-test. Association between EL_diastole with AI\% and RAI\% was evaluated using Pearson's correlation.

\section{Results}

The $95 \% \mathrm{CI}$ of healthy controls was $[6.23 \%, 11.66 \%]$ for AI $\%$ and $[3.9 \%, 7.11 \%]$ for RAI\%. In 11 patients $\mathrm{AI} \%$ was above $95 \% \mathrm{CI}(20.4 \pm 6.59 \%)$. In these patients, EL_diastole was significantly increased relative to controls (patients: $0.53 \pm 0.15 \mathrm{~mJ}$ vs controls: $0.31 \pm 0.13 \mathrm{~mJ}, \mathrm{p}<0.001$ ) while the 10 patients below upperlimit $95 \% \mathrm{CI}$ showed no significant difference relative to controls (patients: $0.44 \pm$ $0.17 \mathrm{~mJ}, \mathrm{p}=0.07$ ). In 13 patients RAI\% was above $95 \% \mathrm{CI}$ $(18.46 \% \pm 7.5 \%)$. These patients presented a significant increase in EL_diastole relative to controls $(0.48 \pm 0.18 \mathrm{~mJ}$, $\mathrm{p}=0.005)$ and to the 8 patients below upperlimit $95 \% \mathrm{CI}$ $(0.31 \pm 0.11, \mathrm{p}=0.02)$. These 8 patients showed no significant difference to controls' EL_diastole $(\mathrm{p}=0.94)$. In patients, EL_diastole was significantly positive correlated with $\mathrm{AI} \%(\mathrm{R}=0.63, \mathrm{p}=0.002)$ and with $\mathrm{RAI} \%(\mathrm{R}=0.62$, $\mathrm{p}=0.002$ ) (Figure 1).

\section{Conclusions}

This is the first study to reveal the adverse impact of increased (retained) apical inflow on LV energy loss. Elevated viscous energy loss in patients reflects increased blood flow friction. This could potentially result in apical blood stagnation. Future-studies are needed to assess the 


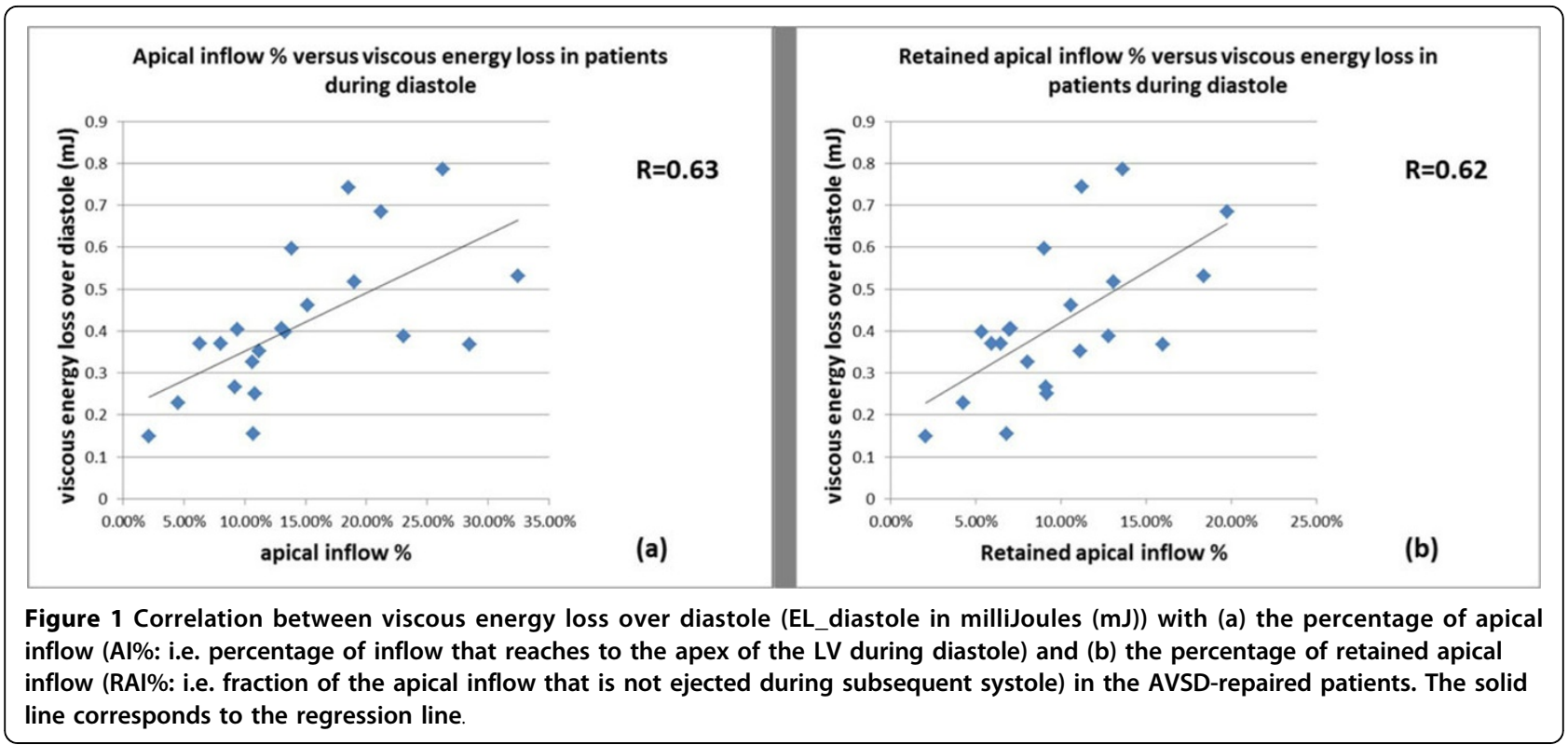

impact of the reported association on LV function. The provided 4D flow workflow may permit a non-invasive tool to assess blood inflow efficiency in different patient groups.

\section{Authors' details}

'Division of Image Processing, Radiology, Leiden University Medical Center (LUMC), Leiden, Netherlands. '2Department of Paediatric Cardiology, Leiden University Medical Center, Leiden, Netherlands. ${ }^{3}$ Department of Intelligent Systems, Delft University of Technology, Delft, Netherlands.

Published: 27 January 2016

\section{References}

1. Calkoen, et al: Invest Radiol 2015.

2. Barker, et al: MRM 2013.

doi:10.1186/1532-429X-18-S1-P24

Cite this article as: ElBaz et al:: Apical inflow is associated with

increased energy loss during left ventricular diastole in patients with a

repaired atrioventricular septal defect: a $4 \mathrm{D}$ flow MRI study. Journal of

Cardiovascular Magnetic Resonance 2016 18(Suppl 1):P24.

Submit your next manuscript to BioMed Central and take full advantage of:

- Convenient online submission

- Thorough peer review

- No space constraints or color figure charges

- Immediate publication on acceptance

- Inclusion in PubMed, CAS, Scopus and Google Scholar

- Research which is freely available for redistribution

Submit your manuscript at www.biomedcentral.com/submit 